\title{
Innovation in the Manufacturing Sector: The Case of Serbia
}

\author{
Ljiljana Kontic \\ Faculty of Legal and Business Studies, Novi Sad, Serbia
}

\begin{abstract}
The paper presents the results of research on innovation activities of manufacturing firms in Serbia. In order to answer the question how innovation takes place in one transition country, key influencing factors were identify (i.e., firm's size, age, ownership, industry sector, personnel qualifications and experience). Based on the analysis of a sample comprising 73 firms, the study tried to highlight certain innovation barriers, which may have a negative impact on the total efficiency of economic performance, and growth and development of manufacturing firms in Serbia. Comparing overall innovation activities of Serbian firms to the other transition countries, it can be concluded that majority of the firms had innovation performances below the level EU-27. This study draws out the potential contributions to existing literature of managing innovation in Serbia.
\end{abstract}

Keywords: innovation factors, innovation networks, manufacturing sector, strategy, Serbia

\section{Introduction}

Innovation in the manufacturing sector is a very complex process. Since 1996, a very limited number of articles on manufacturing sector innovation have published. The rate of published articles on manufacturing sector innovation significantly increased in the period 1996-2003 due to the series of Community Innovation Surveys (CIS) conducted in Europe (Becheikh, Landry, \& Amara, 2006, p. 646). The vast majority of innovation studies have been conducted in developed countries. Only a few studies utilize data from transition countries (Kramer, 2009; Koschatzky, Bross, \& Stanovnik, 2001; Leskovar-Spacapan \& Bastic, 2007). This raises important question about the transferability and relevance of innovation studies in Western Europe to an explanation of the innovation activities in transition economies.

Serbia's small market is faced with great challenges. Serbian industry had lost large portion of foreign and domestic market due to resolution of former Yugoslavia and influence of the economic sanctions. The share in domestic market had significantly shrunk as a result of opening market and the expansion of multinational corporations. The choice to analyze manufacturing firms is dictated by importance of this section for the Serbian economy in the terms of the total results (Statistical Office of the Republic of Serbia, 2010). Regarding innovation activities of the manufacturing firms in Serbia a number research questions arise. In this study, two

Ljiljana Kontic, Ph.D., Assistant Professor, Faculty of Legal and Business Studies.

Correspondence concerning this article should be addressed to Ljiljana Kontic, Faculty of Legal and Business Studies, Novi Sad, Serbia. E-mail: ljiljana.kontic@yahoo.com. 
questions are of special interest: (1) Which internal and contextual factors influence the various type of innovation? (2) Which are the main innovation obstacles? To answer these questions, empirical research was conducted in the most successful manufacturing firm in Serbia. The purpose of the research was to determinate key influencing factors in innovation processes in selected manufacturing firms.

While there has been the same research on the innovation activities in Serbian firms (MSEP, 2007; The World Bank Enterprise Survey, 2009; European Innovation Scoreboard, 2010), little has been written about innovation activities in manufacturing sector. This paper will suggest key issues which need to be addressed when considering the innovation in manufacturing sector in one transition economy.

This paper is organized as follows. The next section reviews the extant literature on innovation in manufacturing sector and proposes the conceptual model. The third section discusses the research context. The fourth section outlines the research methodology used in this study. The final sections discuss the main results and present the main conclusions and implications of this study.

\section{Theoretical Background}

Many researchers have studied the innovation in manufacturing firms and they focused on examination factors which determinate the innovative behaviour and capacity of the firms. The evidence from extensive study of 78,000 individual firms from 22 European countries favours explanations that relate firm-level variety in innovation behaviour as well as sectoral contingencies (Peneder, 2010). Several factors have been analyzed in the previous literature. Based on extensive review of empirical articles, a conceptual model has been proposed (see Figure 1).

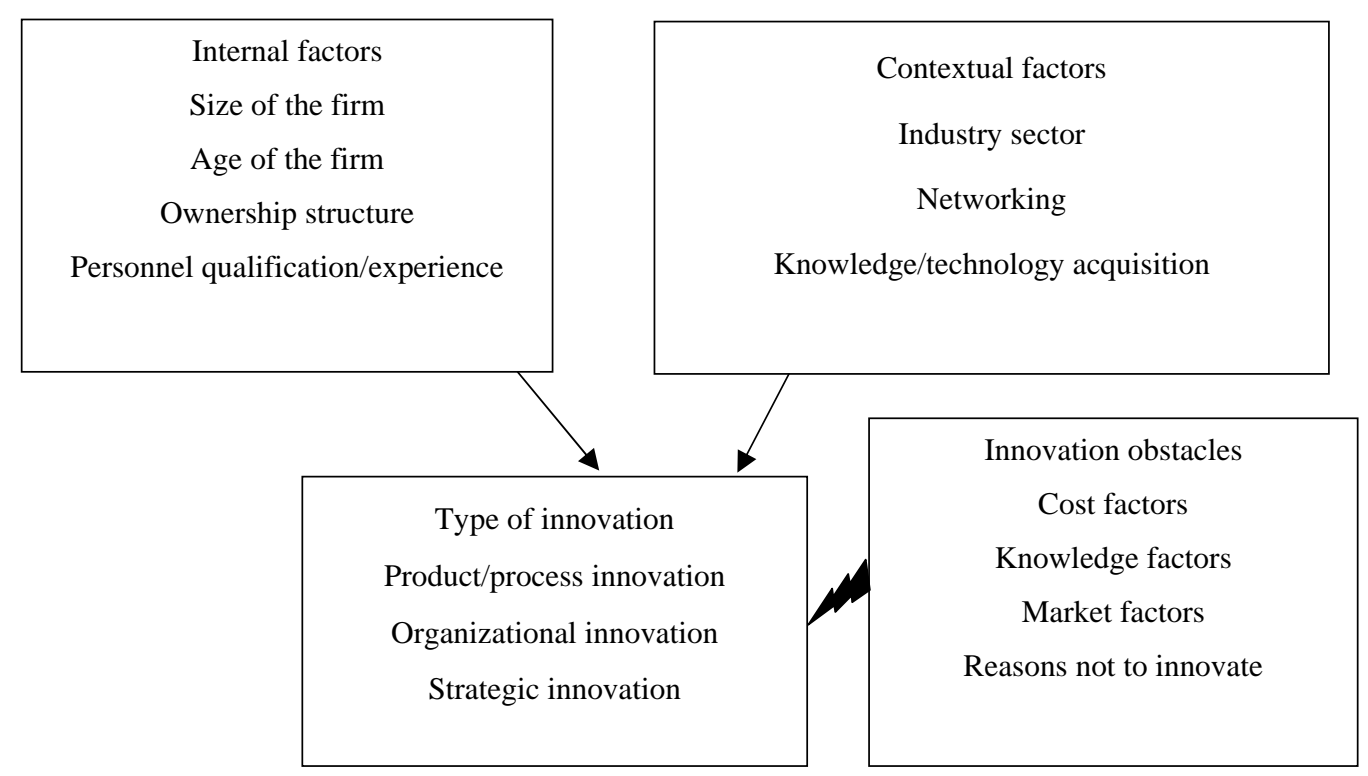

Figure 1. Conceptual model. Source: Adopted from Becheikh et al. (2006).

Since the late 1960s, organizational theorists have been tried to identify the distinguishing characteristics of innovative organizations at the firm-level (Souitaris, 2002). Firm size has been viewed as an explanatory variable of innovating behavior by many authors (Schumpeter, 1942; Stock, Greis, \& Fischer, 2002; Veugelers \& 
Cassiman, 1999; Greve, 2003; Tsai, 2001). Following Schumpeter’s statement that innovation activity increases more than proportionally with firm size, the vast majority of the studies found that the size had positive effect on innovation (Tsai, 2001; Stock et al., 2002; Veugelers \& Cassiman, 1999; Michie \& Sheehan, 2003). Other internal factors such as firm's age, past performance and ownership have been less examined. With regard to effect of firm's age on innovation activity, Sørensen and Stuart (2000) suggested that older firms innovate more than younger ones, on the one hand. On the other hand, Freel (2003) suggested that older firms are less innovative than younger ones because they have established routines which create resistance to external changes.

Previous researches concern effect of ownership structure on innovation activities came to dual conclusions. Positively and significant correlation between foreign ownership and innovation was founded in the research of Michie and Sheehan (2003). Other study maintained that the foreign ownership had negative effect on innovation due to lack of research and development (R\&D) function (Love \& Roper, 2001). One of the most important influencing factors of innovation is high educated, technically qualified and experienced staff (Freel, 2003; Souitaris, 2002; Dobni, 2006).

Besides internal factors, innovation activities are affected by various contextual factors such as industry sector, networking and knowledge/technology acquisition. Previous studies found strong industry effects on innovation (Cassiman \& Veugelers, 2004; Andrijasevic, 2005). Precisely, firms from the high-tech industries (e.g., pharmaceutical, chemicals, and electrics) had intensive innovation activities than the firms from low-tech industries (e.g., wearing apparel, manufacture of furniture). Some of the studies revealed positive correlation between innovation and collaboration with customers, competitors, consultant or universities (Kaufmann \& Tödtling, 2001; Souitaris, 2002) that supported the evolutionary perspective of the innovation process (Dosi, Freeman, Nelson, Silverberg, \& Soete, 1988; Kaufmann \& Tödtling, 2001). Certain high-tech firms track results of collaboration by comparing time to market for in-house and partnered product development (Linder, Jarvenpaa, \& Davenport, 2003).

Some studies found that networking had no influence on firm's innovation activities (Freel, 2003; Love \& Roper, 2001). Innovation is extremely dependent on the availability of internal and external knowledge. Knowledge and technology acquisition can take many forms, such as acquisition of machinery, equipment and software, licensing, know-how etc.. Firms have used acquisition of external knowledge to improve the speed and quality of innovation, their access to disruptive new ideas and their ability to make tough priority decisions. Knowledge is catalyst of innovation process in firms (Ahuja \& Katila, 2001; Souitaris, 2001). Some studies reported non-significant influence of the knowledge acquisition on innovation (Love \& Roper, 2001; Kaufmann \& Tödtling, 2001).

Main characteristics of innovation process are complexity and stochastically. In this process, there are numerous barriers. According to Community Innovation Surveys (CIS), major obstacles can be divided into following four groups: (1) Cost factors (lack of funds, lack of finance from sources outside the firm, innovation costs too high); (2) Knowledge factors (lack of qualified personnel, lack of information on technology, lack of information on markets, difficulty in finding cooperation partners for innovation); (3) Market factors (market dominated by established firms, uncertain demand for innovative); and (4) Reasons not to innovate (no need due to earlier innovations, no need because there is no demand for innovations). 
For the purpose of this survey, innovation is defined, according to CIS methodology (OECD \& Eurostat, 2005, p. 5) as follows:

Innovation is the implementation of new or significantly improved product or processes, a new marketing method, or a new organisational method in business practices, workplace organisation or external relations used to produce or supply all goods or services that the business has introduced, regardless of their origin. These may be new to the business or new to the market.

With regard to product/process innovation, several studies have showed that product and process innovations follow different paths (Sternberg \& Arndt, 2001; Michie \& Sheehan, 2003; Freel, 2003). Moreover, same influencing factors would have different effects on innovation activities based on firm consideration only the product innovation, the process innovation or both (Michie \& Sheehan, 2003).

Recent studies revealed that one of the basic function of innovation management was the continuous adjustment of the organization that starts with collecting knowledge about innovation (Tomala \& Sénéchal, 2004). Second task is building the new organizational structures that enables manage innovation more efficiently in order to increasing market competitiveness. Commonly proposed way to support innovation is a flexible organization (Sundström \& Zika-Viktorsson, 2009). Main aim of strategic and organizational changes is creating preconditions for innovation activities. These changes are common in firms from transition economies due to privatization processes.

\section{Research Context}

Serbia has been chosen as the research context for the following key reasons. Serbia is one of the Western Balkans countries (Albania, Bosnia and Hercegovina, Former Yugoslav Republic of Macedonia, Croatia, Montenegro and Serbia). After a decade of declining economic performances, Serbia as well as other countries in the region has experienced renewed economic growth. It was estimated that total economic activity in 2010, measured by GDP and expressed at constant prices of 2002, increased by $1.5 \%$ in comparison to the previous year. Industrial production increased by $3.0 \%$ in 2010. Such increase was mainly caused by increase in the section of manufacturing, and mining and quarrying (Statistical Office of the Republic of Serbia, 2010). The Serbian economy adopted a structural adjustment programme in October 2000. During the period 2000 to 2008 , privatization and restructuring processes have been dominated in Serbian industry.

According to the author's knowledge, three national survey were conducted in Serbia: National innovation audit (MSEP, 2007), The World Bank Enterprise Survey, and European Innovation Scoreboard (2010). Although these studies used different methodology and innovation indicators the overall result is the same-Innovation activities of firms in Serbia are weak.

The results of national innovation audit survey of over 600 firms and 40 innovation support organization revealed a number of weaknesses. The employment in medium and high-tech manufacturing firms is significantly below that of EU-27. The investment in innovation is very low. More than 50\% of observed firms are concentrated innovation activities in acquisition of machinery, equipment and software and related training (MSEP, 2007).

According to The World Bank Enterprise Survey (2009), Serbia is classified in Eastern Europe and Central Asia region and in upper middle income group (GNI per capita was US \$ 4,730.00). With regard to innovation 
and workforce indicators, firms in Serbia had similar performances as firms in aforementioned groups. These innovation performances are significantly below the level EU-27 countries.

In the latest Community Innovation Survey (CIS), firms from Serbia have been participated for the first time (European Innovation Scoreboard EIS, 2010). According to the report, Serbia is in the group of catching-up countries, with innovation performance well below the EU27 average. Relative strengths, compared to the country's average performance, are in Economic effects and relative weaknesses are in linkages and entrepreneurship, throughputs and innovators.

The choice to analyze manufacturing firms is dictated by importance of this section for the Serbian economy in terms of the total results (Statistical Office of the Republic of Serbia, 2010, pp. 14-18): relatively large concentration of manufacturing firms (22.6\% of total firms in Serbia), total number of employees (38.6\% were engaged in manufacturing sector), generated turnover in manufacturing was $31.6 \%$ of the total turnover, in the total value added manufacturing sector had $32.1 \%$, and taking into account personnel costs, manufacturing firms had a biggest share with $36.7 \%$.

\section{Research Methodology}

The research methodology was based on interviews with top managers and R\&D managers in 73 manufacturing firms. In selecting companies three criteria were used: (1) good financial performances (operation revenues, capital, and profits), (2) industry sector; (3) number of employees. A source for the financial performances was a ranking of the 300 most successful enterprises in Serbia in 2006 by operating revenues, according to the Economist Journal (EMG, 2007).

Structure of the selected sample according to NACE Rev. 1.1. is:

- Manufacture of food products and beverages-17 firms;

- Manufacture of chemicals and chemical products-10 firms;

- Manufacture of electrical machinery and apparatus-8 firms;

- Manufacture of metal products-6 firms;

- Manufacture of wearing apparel—6 firms;

- Manufacture of rubber and plastic products—6 firms;

- Manufacture of furniture-5 firms;

- Manufacture of office machinery and computers-5 firms;

- Non-metal mineral products-4 firms;

- Manufacture of medical, precision and optical instruments-4 firms;

- Manufacture of tobacco products-2 firms.

According to the number of employees, research sample was consisted of $43.84 \%$ small firms (10 to 49 employees), 30.14\% large firms (more than 250 employees), and 26.02\% medium-sized firms (50 to 249 employees).

Prior to the survey, in order to provide more complete information for the study, the prototype of questionnaire was developed based on Oslo Manual (2005). Through simple data analyses, feedback and discussions with the seven $R \& D$ managers, the final version of the questionnaire was developed. This stage has 
been particular useful since it provided a direct insight into how specific phenomena, found actual application in the industrial practice within the context under investigation. The final version of the questionnaire comprised 24 questions classifying into following four sections: Section A: General business information; Section B: Innovation activities; Section C: Type of innovation; and Section D: Context for innovation. Each question was formulized as statements and respondents were ask to answer to categorical questions (by choosing yes or no) and to estimate degree of importance using a Likert scale ranging from 1 to 5 . On the "importance" scale, a " 1 " indicates that the statement according to him/her is of very minor importance, while statements that score " 5 " is perceived as having very high importance.

For the purpose of data analysis, descriptive statistics and Pearson correlation coefficient were computed.

First, the author personally contacted respondents then send the questionnaires by mail. The research took place during 2009, but results about innovation activities related to period 2005-2008.

\section{Main Findings and Contributions}

The results of empirical research have been presented according to the aforementioned conceptual model (see Figure 1).

\section{Internal Factors}

It is important to note that 36 of 73 firms (49.31\% selected firms) implemented product and/or process innovations during the 3 years period (January 1, 2005-December 31, 2008). More than 75\% of the observed firms introduced organizational, managerial and/or strategic innovations during the same period. Privatization has a large impact on the aforementioned innovations. In some cases organizational changes can be riskier than strategic change. Fortunately, the organizational restructuring have been successful in $84.82 \%$ observed firms (Kontic, 2007).

There appears to be a strong correlation between innovation activity and firm size: In large and medium-sized firms, the share of innovative firms is generally higher than in small ones (see Table 1). A firm needs to be large enough to have own R\&D department. Small firms do indeed innovate, but they do not always have sufficient resources (financial, human, etc.) to benefit from their innovations.

Table 1

Organizational Size and Product/Process Innovation

\begin{tabular}{lllll}
\hline \multirow{2}{*}{ Firm size } & \multicolumn{3}{c}{ Strategic choice } & Total (\%) \\
\cline { 2 - 5 } & Product innovation & Process innovation & Product and process innovations & 22.22 \\
\hline Small (\%) & 13.89 & 8.33 & 0 & 36.11 \\
Medium (\%) & 8.33 & 25 & 2.78 & 41.67 \\
Large (\%) & 2.78 & 33.33 & 5.55 & 100.0 \\
Total (\%) & 25 & 66.67 & 8.33 & \\
\hline
\end{tabular}

In observed firms, the relatively high share of innovative firms that were process innovators. The attitude towards innovation of observed managers in manufacturing firms showed that in most cases, innovations were implemented according to process innovation procedures. Thirty four point five percent of selected firms did not have procedures for introducing process innovations. More than a quarter of innovations remained unused. 
The share of product innovators was relatively lowers (25\% of selected firms). Only three firms invested simulating in product and process innovation. Regarding strategic choice to invest in product and/or process innovation, the results revealed that small firms are favor to product innovation while large firms more invest in process innovations. This is opposite to Linder et al.'s (2003, p. 45) study that founded “Executives think primarily about new products when considering innovation and much less often about such areas as creating new business models or revamping business processes".

At the end of 2008, due to the impact of the global economic crisis, industrial output in manufacturing was decline (-15.8\%). The effects of the crisis were increasingly felt in 2009. The results of first six month in 2009 showed high level of decline in total industrial production (-17.4\%), particular in manufacturing (-22.1\%). All observed firms, regardless the size, have reduced their R\&D expenditures.

Some results of this study were compatible to Michie and Sheenan's (2003, p. 134) study such as:

Firm's age is negatively correlated with the product innovation and positively correlated with the process innovation. Foreign ownership is significantly positive correlated with all type of innovation (especially with organizational and strategic innovations).

Personnel qualification/experience is positively correlated with the probability of all innovations. It is noted that only $30 \%$ of observed manufacturing firms have skilled production employees. The $20 \%$ of top managers and R\&D managers had between 11-20 years of work experience in the firm sector.

\section{Contextual Factors}

Intensive innovation activities were evidenced in sector of manufacture of chemicals and chemical products (90.00\% of observed firms) as well as manufacture of rubber and plastic products (83.83\% of observed firms). None innovation have been implemented in manufacture of furniture. The low level of innovation activity was evidenced in observed firms in sector of manufacture of food products and beverages (29.41\%) and in sector of manufacture of wearing apparel (16.67\%).

Most of observed firms in the typical high-tech industries, especially chemicals and electrics, have intensive innovation activities compared to traditionally low-tech sectors, like wearing apparel and manufacture of furniture. This result is in line with most other studies, which found strong industry effects on innovation (Cassiman \& Veugelers, 2004; Andrijasevic Matovac, 2005).

As information plays a key role for innovation, it is necessary to identify the most important sources of information for innovative firms. The most used sources of information in observed firms were:

(1) Suppliers (76\% of firms);

(2) Competitors (24\% of firms);

(3) Customers (19\% of firms);

(4) Internal sources (11\% of firms).

The questionnaire differentiated between seven different cooperation partners:

- Other firms within the same firms group;

- Competitors or other firms of the same sector;

- Clients or customers;

- Suppliers of equipment, materials, components or software; 
- Universities or other higher education institutions;

- Government or public research institutes;

- Consultants, commercial labs, or private R\&D institutes.

To summarize the results on cooperation, it should be said that $89 \%$ of innovative firms did cooperate, mostly with customers, suppliers and competitors. Less common ways are cooperation with scientific research institutes as well as universities. This goes in line with results of one study about intellectual capital in large and medium industrial firms in Serbia (Kontic \& Cabrilo, 2009). In the observed firms lack of collaboration with universities and research institutes, partly results in insufficient product and process innovation.

Around two thirds of Serbian innovative firms were involved in the acquisition of machinery, equipment and software. Less than $20 \%$ of firms acquired external knowledge. Internal research and development was conducted in $11.11 \%$ of selected firms.

\section{Innovation Obstacles}

The innovation activity is likely to be abandoned after it has begun for a number of different reasons, and a large percentage of Serbian firms (52.63\%) highlighted this hampering effect of innovation.

Respondents were asked to classify eleven factors hampering innovation according to their degree of importance. These factors covered the four groups listed in the Figure 1.

As far as obstacles to innovation are concerned, the results indicate that in majority of the observed firms cost factors (more than $89 \%$ ) and knowledge factors (58\% of industrial firms) are dominant obstacles.

Lack of funds within the firm appears to be the most important hampering factor for innovation process, followed by the financing from outside sources.

The lack of qualified personnel is a major barrier to innovation in the group of knowledge factors. More than quarter respondents have identified labor skill level as a major constraint to innovation activities. This barrier was dominant in small firms. On the contrary to the study conducted in developing country that revealed the existing personnel were in a position to productively use the technologies (Efstathiades, Tassou, Oxinos, \& Antoniou, 2000).

\section{Conclusion}

This study makes two important contributions to the existing literature. Firstly, the findings contribute to our understanding of innovation activities in transition economy. The paper suggests that innovation studies in Western Europe have limited transferability and relevance to explanation innovation activities in transition economies. Secondly, the study provides insights in the key influencing factors and barriers to innovation activities in manufacturing firms in Serbia.

Notwithstanding the results of this study, there are three main limitations. The study was conducted in a specific national (Serbia) and industry context (manufacturing firms). The relatively small sample size was examined.

The results represent a basis for future research that should expand into all industries as well as service sector and embody large sample of firms. Possible direction for further study will be detail investigation innovation performances in selected sample during the crisis and compare them with innovation activities before economic crisis. 


\section{References}

Ahuja, G., \& Katila, R. (2001). Technological acquisitions and the innovation performance of acquiring firms: A longitudinal study. Strategic Management Journal, 22(3), 197-220.

Andrijasevic Matovac, V. (2005). Innovation activities in Croatian firms-Industry differences. Economic Review, 56(3-4), 204-220.

Becheikh, N., Landry, R., \& Amara, N. (2006). Lessons from innovation empirical studies in the manufacturing sector: A systematic review of the literature from 1993-2003. Technovation, 26, 644-664.

Cassiman, B., \& Veugelers, R. (2004). In search of complementarity in the innovation strategy: Internal R\&D and external knowledge acquisition. Leuven: IESE Business School and University of Leuven.

Dobni, C. B. (2006). The innovation blueprint. Business Horizons, 49, 329-339.

Dosi, G., Freeman, C., Nelson, R., Silverberg, G., \& Soete, L. (Eds.). (1988). Technical change and economic theory. London: Pinter.

Efstathiades, A., Tassou, S. A., Oxinos, G., \& Antoniou, A. (2000). Advanced manufacturing technology transfer and implementation in developing countries: The case of the Cypriot manufacturing industry. Technovation, 20, 93-102.

EMG. (2007). Top 300 most successful (3rd ed.). Belgrade: Economist Magazine Group.

European Commission Enterprise and Industry. (2010). European innovation scoreboard (EIS) 2009. PRO INNO Europe paper No. 15.

Freel, M. S. (2003). Sectoral patterns of small firm innovation, networking and proximity. Research Policy, 32, 751-770.

Greve, H. R. (2003). A behavioral theory of R\&D expenditures and innovations: Evidence from shipbuilding. Academy of Management Journal, 46, 685-702.

Kaufmann, A., \& Tödtling, F. (2001). Science-industry interaction in the process of innovation: The importance of boundary-crossing between systems. Research Policy, 30, 791-804.

Kontic, Lj. (2007). Restructuring and privatization of large enterprises in Serbia. Belgrade: Institute of European Studies.

Kontic, Lj., \& Cabrilo, S. (2009). A strategic model for measuring intellectual capital in Serbian industrial enterprises. Economic Annals, 183, 89-117.

Koschatzky, K., Bross, U., \& Stanovnik, P. (2001). Development and innovation potential in the Slovene manufacturing industry: Analysis of an industrial innovation survey. Technovation, 21, 311-324.

Leskovar-Spacapan, G., \& Bastic, M. (2007). Differences in organizations’ innovation capability in transition economy: Internal aspect of the organizations' strategic orientation. Technovation, 27, 533-546.

Linder, J. C., Jarvenpaa, S., \& Davenport, T. H. (2003, Summer). Toward an innovation sourcing strategy. MIT Sloan Management Review, 43-49.

Love, J. H., \& Roper, S. (2001). Location and network effects on innovation success: Evidence for UK. German and Irish manufacturing plants. Research Policy, 30, 313-332.

Michie, J., \& Sheehan, M. (2003). Labour market deregulation, “flexibility” and innovation. Cambridge Journal of Economics, 27(1), 123-143.

Ministry of Science and Environmental Protection. (2007). Innovative Serbia: A strategy for action (4th ed.). Belgrade: Ministry of Science and Environmental Protection.

OECD, \& Eurostat. (2005). Oslo manual: Guidelines for collecting and interpreting innovation data (3rd ed.). Paris: OECD, Directorate for Science, Technology and Industry and Eurostat Working Party on Science, Technology and Innovation Statistics.

Peneder, M. (2010). Technological regimes and the variety of innovation behaviour: Creating integrated taxonomies of firms and sectors. Research Policy, 39, 323-334.

Schumpeter, J. A. (1942). Capitalism, socialism and democracy. New York: Harper.

Sørensen, J. B., \& Stuart, T. E. (2000). Aging, obsolescence, and organizational innovation. Administrative Science Quarterly, 45(1), 81-112.

Souitaris, V. (2001). External communication determinants of innovation in the context of a newly industrialised country: A comparison of objective and perceptual results from Greece. Technovation, 21, 25-34.

Souitaris, V. (2002). Technological trajectories as moderators of firm-level determinants of innovation. Research Policy, 31, 877-898.

Statistical Office of the Republic of Serbia. (2010). Statistical bulletin-Basic results of business activity of enterprises and 
entrepreneurs in the year 2008. Belgrade: Statistical Office of the Republic of Serbia.

Stock, G. N., Greis, N. P., \& Fischer, W. A. (2002). Firm size and dynamic technological innovation. Technovation, 22, 537-549. Sundström, P., \& Zika-Viktorsson, A. (2009). Organizing for innovation in a product development project Combining innovative and result oriented ways of working-A case study. International Journal of Project Management, 27, 745-753.

The World Bank Enterprise Survey. (2009). Serbia Country Profile 2009. Washington, D.C.: The World Bank.

Tomala, F., \& Sénéchal, O. (2004). Innovation management: A synthesis of academic and industrial points of view. International Journal of Project Management, 22(4), 281-287.

Tsai, W. (2001). Knowledge transfer in intraorganizational networks: Effects of network position and absorptive capacity on business unit innovation and performance. Academy of Management Journal, 44, 996-1004.

Veugelers, R., \& Cassiman, B. (1999). Make and buy in innovation strategies: Evidence from Belgian manufacturing firms. Research Policy, 28, 63-80. 